\title{
Fuentes y archivos para el análisis de las transformaciones del movimiento sindical y los trabajadores durante el Stronismo (1954-1989)
}

Sources and archives for the analysis of the union' transformation and the workers movement during the Stroessner's regime (1954-1989)

Ignacio González Bozzolasco

Universidad Católica de Asunción. Programa Nacional de Incentivo a los Investigadores-

Consejo Nacional de Ciencia y Tecnología, Paraguay

igonbo@gmail.com

\section{Resumen:}

El artículo hace un recorrido por las principales producciones bibliográficas, así como por los principales archivos al respecto del movimiento sindical y los trabajadores durante el gobierno del general Alfredo Stroessner (1954-1989). Se presenta de manera sucinta la producción acerca del movimiento obrero paraguayo de cada década y sus características a partir de 1980 en adelante. Además, se ofrece una descripción general de los fondos documentales con material relevante sobre el mundo del trabajo en Paraguay.

Palabras ClaVe: Paraguay, Movimiento-sindical, Stronismo, Fuentes-y-archivos.

\section{ABSTRACT:}

The article reviews the main bibliographic works and archives about trade unions and workers during the government of General Alfredo Stroessner (1954-1989). It also presents a brief description of the relevant literature about the Paraguayan labor movement from the 1980s to the present. In addition, the article offers a general description of important documentary collections with relevant material about labor relations in Paraguay.

KEYWORDS: Paraguay, Trade unions, Stronism, Sources and archives.

\section{INTRODUCCIÓN}

A lo largo de este trabajo, buscamos presentar un recorrido general a través de los principales aportes bibliográficos y los fondos documentales más relevantes para el análisis de las transformaciones del movimiento sindical y de los trabajadores, durante el régimen autoritario del General Alfredo Stroessner, vigente entre los años 1954 y 1989.

Los estudios sobre el movimiento obrero y los sindicatos en Paraguay se destacan por su frecuente ausencia en el amplio campo de la historia obrera latinoamericana. ${ }^{1}$ En gran medida, esto se corresponde con una reducida producción por parte de las ciencias sociales paraguayas, en comparación con la región. Si las ciencias sociales en Paraguay lograron su desarrollo y consolidación como un campo de producción de saberes durante las décadas de 1960 y 1980 (Soler, 2018), los estudios al respecto del mundo del trabajo permanecieron muy rezagados en ese proceso. Así, las investigaciones centradas en el mundo rural, primeramente, y en los análisis del régimen autoritario dirigido por Alfredo Stroessner y los inicios de la transición, con posterioridad, prevalecieron como temas preponderantes en las agendas de investigación sobre Paraguay. Estructuramos el artículo a partir de tres secciones. En la primera, se ofrece una breve caracterización del stronismo como régimen político autoritario, a partir de los conceptos y argumentos de mayor consolidación a este respecto. En la segunda, se exponen, a grandes rasgos, los trabajos producidos 
acerca del movimiento sindical paraguayo, así como los principales núcleos temáticos tratados por los mismos. En la tercera, se hace una presentación de los archivos y demás fondos documentales disponibles para la investigación acerca del movimiento obrero paraguayo. Finalmente, a modo de cierre, formulamos algunos de los desafíos considerados para el desarrollo de una nueva agenda de investigación sobre el movimiento sindical paraguayo.

\section{El STRonismo: un NUEvo RÉGIMEN POLÍtico}

El ascenso al poder por parte del general Alfredo Stroessner (1954) significó un parte aguas en el escenario político paraguayo, tras un largo periodo de inestabilidad política, imperante desde el retorno del Partido Colorado (1948). Si entre los años 1948 y 1954 se sucedieron siete presidentes de ese partido, la mayoría de ellos habían sido derrocados por medio de golpes de Estado.

Como apunta Benjamín Arditi (1992, p. 15), este hecho no significó un golpe de Estado más ni, únicamente, otro cambio de gobierno. Más allá de esto, marcó el punto de partida para la creación de un nuevo orden con renovadas reglas de juego político, así como una nueva institucionalidad jurídica y política que será plasmada años más tarde en la nueva Constitución paraguaya de 1967. Este nuevo régimen en formación logró consolidarse a partir de los siguientes ejes centrales de sustento:

(...) el fortalecimiento del Estado como núcleo decisionista soberano y la imposición de orden y estabilidad política a partir del Estado, estableciendo, por un lado, una legalidad capaz de plasmar normativamente el orden fáctico instituido y, por otro, desarrollando una estrategia simultánea de desestructuración corporativa de la sociedad civil (Arditi, 1992, p. 15).

A lo largo de sus primeros años en el poder, Stroessner tuvo que atravesar una fase de consolidación, con purgas al interior del Partido Colorado y de las Fuerzas Armadas, además de represión a sectores organizados de la sociedad civil que manifestaban sus críticas. Así, para finales de la década de 1960, el régimen ya había adquirido un control total sobre el partido de gobierno, las esferas militares, la oposición tolerada y las organizaciones sociales con funcionamiento permitido (Nickson, 2011, p. 268).

La nueva Constitución de 1967 tuvo como principal intención el dotar de legitimidad y argumentos democráticos al Stronismo (Soler, 2012, p. 122). De esta forma, el nuevo orden político amplió formalmente el juego político, dando reconocimiento legal a cierta oposición, pero sin amenazar su capacidad de control político. El stronismo se había dado cuenta "de que no era necesario clausurar el espacio público para instalar una autocracia; bastaba con recodificarlo de manera de vaciarlo de toda eficacia” (Arditi, 1992, p. 38).

Este nuevo régimen político dio renovados impulsos a un postergado proceso de modernización capitalista, al cual Luis Galeano (2016) caracterizó como “modernización conservadora, tardía y parcial”. La denominó como modernización conservadora, debido al rol central y protagónico jugado por el Estado autoritario consolidado por Stroessner. La calificó como modernización tardía, puesto que, a diferencia de la mayoría de los países de la región, la modernización capitalista agraria tuvo lugar en Paraguay recién avanzada la segunda mitad del siglo veinte. Por último, la definió como modernización parcial porque su afianzamiento se dio recién durante la década del 90, luego de la caída del régimen stronista y el inicio de la transición a la democracia (Galeano, 2016, p. 11).

\section{LOS TRABAJOS SOBRE EL MOVIMIENTO SINDICAL PARAGUAYO}

Las primeras incursiones en el terreno de la historia obrera fueron hechas por militantes e intelectuales obreros que empezaron a escribir acerca de la clase obrera y sus luchas, durante la primera mitad del siglo veinte. En "El dolor paraguayo" y "Lo que son los yerbales" el periodista y referente obrero anarquista, Rafael Barrett $(1911,1926)$, describe en detalle la situación y las penurias de clase obrera paraguaya a inicios del siglo veinte. Con sus trabajos "Hombres y obras del Sindicalismo Libre en el Paraguay y otros aportes a la historia" y "El sindicalismo libre en Paraguay", el líder sindical del gremio de los tipógrafos, Ciriaco Duarte, rescata a los más sobresalientes referentes del sindicalismo gremialista de finales del siglo diecinueve e inicios 
del veinte, que más tarde fue desplazado por el sindicalismo de cuño socialista. Por último, "Introducción a la historia gremial y social del Paraguay" de Francisco Gaona (2007), líder sindical ferroviario, es sin dudas la obra más pretenciosa. A lo largo de sus tres volúmenes, su trabajo ofrece una amplia mirada de la historia obrera del Paraguay desde finales del siglo diecinueve hasta la primera mitad del veinte.

Fue recién con la recomposición del movimiento sindical en la década de 1980, tras los inicios de la crisis del sindicalismo de Estado representado por la Confederación Paraguaya de Trabajadores (CPT), que comenzaron a desarrollarse nuevas miradas acerca del sector obrero organizado, estudiando la especial coyuntura atravesada y los periodos anteriores de su historia. Sin embargo, estos esfuerzos se enfrentaron con grandes dificultades. Además de las limitaciones propias de la investigación en el marco de un régimen autoritario en descomposición, se sumó la prácticamente inexistente disponibilidad de acervos documentales de carácter público.

Fue con la crisis del sindicalismo de Estado y la recomposición del movimiento sindical en Paraguay, detonada a finales de la década de 1970 e inicios de la de 1980, que investigadores e investigadoras comenzaron a hacer foco en el mundo del trabajo y el sector obrero organizado de este país. La producción científica sobre estos temas resultaba entonces muy dificultosa, por causa de las muchas restricciones que el régimen imponía para la investigación y el acceso a fuentes. Por esos años, era sumamente intrincado el acceso a datos producidos por los organismos especiales, mientras que una parte significativa de los trabajos provenientes de los gremios, como también de las publicaciones científicas especializadas, eran consideradas como subversivas. En este contexto, mientras que algunas investigaciones se enfocaron en los periodos previos al gobierno de Stroessner (1954-1989), otras se abocaron al estudio de las organizaciones sindicales del periodo en cuestión y sus antecedentes inmediatos. ${ }^{2}$

Así, los esfuerzos iniciales como "Paraguay. Coyuntura Sindical" (Rodríguez, 1982), "Relación EstadoMovimiento Obrero" (Villalba, 1986b) y la serie de "Cronología del Movimiento Obrero Paraguayo 1984-87” (Villalba, 1985, 1986a, 1987, 1988), buscaron realizar una primera descripción general del movimiento sindical y sus rasgos más destacados, a partir de cartillas y documentos de trabajo. A la par, empezaron a desarrollarse algunas investigaciones que, a partir de miradas desde la historia, la sociología y la política, ensayaron análisis sobre las diferentes experiencias de articulación sindical. En el trabajo titulado "Movimiento obrero y procesos políticos en Paraguay" (Salinas, 1984), se ofrece uno de los primeros intentos de reconstrucción histórica del movimiento obrero paraguayo y su relación con los procesos políticos. Esta investigación tiene el mérito de incursionar en un terreno hasta entonces casi inexplorado, por lo que choca con las limitaciones dadas por la carencia de fuentes propia de la época y una noción algo sesgada de los procesos políticos en Paraguay. ${ }^{3}$ Por su parte, en "Breve historia del movimiento obrero paraguayo, 1880-1984" (Nickson, 1987, 1989), se presenta otro acercamiento general a la historia del movimiento obrero, con un breve desarrollo de cada etapa de la historia de los sindicatos a lo largo de un siglo, en un trabajo que fue primeramente publicado en español (1987) y, más tarde, en inglés (1989). En el mismo se destaca un mayor acceso a fuentes documentales, archivos de prensa y testimonios de protagonistas. Con "Significación de la huelga general de 1958" (Casaccia, 1986, 1991) se presenta la primera investigación a profundidad acerca de la huelga general de 1958, llevada adelante por la CPT contra el gobierno de su propio partido político. Producida en el marco de una tesis académica (1986), esta investigación fue publicada recién tras la caída del stronismo (1991).

Desde la perspectiva del estudio de los movimientos sociales y su papel en un contexto de crisis, en "Recesión económica y reconstitución del actor sindical" (Céspedes, 1986) se desarrolla un análisis pionero sobre el nuevo sindicalismo crítico, articulado en un contexto de crisis. Con un enfoque similar, en "La sociedad a pesar del Estado" (Arditi y Rodríguez, 1987) se toma como foco a los movimientos sociales y su relación con el Estado, analizando las características del movimiento obrero en la coyuntura. Mientras que el libro Los sindicatos en Paraguay. Evolución y estructura actual (Barboza, 1987), ofrece uno de los estudios más extendidos de ese periodo, en el que se lleva a cabo un análisis cuantitativo y cualitativo de los sindicatos 
en esa coyuntura (se exponen los resultados de la primera encuesta realizada a los sindicatos en Paraguay), a la vez que expone una sucinta descripción de su evolución histórica.

Tras el derrocamiento de Stroessner (1989), se da inicio a una década de auge en la producción sobre el mundo del trabajo en Paraguay. Las producciones surgidas durante la década de 1990 podrían agruparse en tres grandes núcleos temáticos, según las agendas de investigación de ese momento: en primer lugar, aquellas centradas en el papel de los sindicatos en la recién iniciada transición a la democracia; en segundo lugar, las abocadas a las relaciones laborales y la situación de la clase obrera en Paraguay; y, por último, las que emprendieron una mirada de carácter más histórico de los sindicatos durante el stronismo. Aunque la mayoría de estos trabajos se centraron en desarrollar análisis de la coyuntura en la que fueron producidos, una parte importante de los mismos recupera algunas reflexiones, datos y síntesis analíticas del periodo stronista.

Entre las investigaciones que analizaron el papel de los sindicatos en la transición a la democracia, pueden identificarse dos tipos diferentes. El primero, correspondiente a aquellos trabajos como "Demanda social y política y autoritarismo en Paraguay (1986-1988)" (Céspedes, 1990), “Sindicatos, partidos y transición en Paraguay" (Céspedes, 1991b) y "Sindicalismo y transición” (Céspedes, 1993b) que, a grandes rasgos, se inscriben dentro del debate de la "transitología" (O’Donnell, Schmitter y Whitehead, 1988a, 1988b, 1988c, 1989). Mientras que, el segundo, conformado por otros trabajos como "Sindicalismo y transición. Paraguay 1989” (Rodríguez, 1989a, 1991b), "Lucha sindical y transición política en Paraguay 1990" (Cardozo, 1992) y "Trabajadores y transición paraguaya en perspectiva comparada. Un estudio introductorio" (Smith, 1994), que exploran otros y más diversos abordajes analíticos.

Los trabajos agrupados dentro del amplio eje temático que denominamos como centrado en las relaciones laborales y situación de la clase obrera, tocan aspectos tan variados como la relación gobierno-sindicatos, el sector público, las transformaciones de la clase obrera paraguaya y sus características de consumo. Así, más concentrados en el análisis de las relaciones laborales, se ubican "Las relaciones entre gobierno y sindicalismo en el Paraguay contemporáneo" (Céspedes, 1989), "El contrato colectivo en el Paraguay de la transición” (Céspedes, 1991a, 1992b), "Cambio político y relaciones laborales en el Paraguay" (Céspedes, 1992a), "Relaciones de trabajo en el Sector Público. Paraguay (1989-1993)" (Céspedes, 1993a) y "Situación del trabajo en el Paraguay. Actores, problemáticas y desafíos" (Cristaldo, 1998). En tanto que, mayormente relacionadas con la situación de la clase obrera, se ubica el trabajo titulado "La formación de una nueva clase obrera. Paraguay 1989-1990" (Rodríguez, 1991a). ${ }^{4}$

En menor número, otros trabajos realizaron una mirada de carácter histórico de los sindicatos durante el stronismo, ya sea recuperando el aporte de fuentes bibliográficas, como relevando los testimonios de sus protagonistas (muchos de ellos militantes sindicales exiliados, retornados al país luego de la caída de Stroessner). En esta línea, pueden ubicarse "Situación actual de la historiografía sobre el movimiento obrero paraguayo" (Rodríguez, 1989b), “Cuadernos de Historia Obrera. 1978 - 1991” (Villalba, 1992) y "Huelga de 1958 en el relato de sus protagonistas” (Moran y Villalba, 1994).

A partir del inicio del nuevo milenio, la producción con respecto al mundo del trabajo en Paraguay experimentó una gran merma, probablemente, influenciada por las modificaciones en las prioridades regionales de investigación sobre la temática durante la década anterior (De la Garza, 2016). Si bien los temas laborales, en general, y sobre el sindicalismo, en particular, representaron siempre una cantidad relativamente baja en el conjunto de las producciones científicas sobre Paraguay en comparación con la región, en este periodo se observa un completo abandono de los mismos. Como notoria excepción, fueron publicados sobre el periodo stronista "A History of Organized Labor in Uruguay and Paraguay" (Alexander y Parker, 2005) e "Itaipú y la lucha de los trabajadores" (Coronel, 2009), así como una compilación de trabajos producidos durante la década anterior bajo el título "Autoritarismo, Sindicalismo y Transición en el Paraguay, 1986-1992" (Céspedes, 2009). ${ }^{5}$

Con el inicio de la década en curso, la producción sobre el movimiento obrero paraguayo fue arrancando de nuevo, aunque tímidamente, retomando el interés sobre el periodo stronista. Así, trabajos como "El 
movimiento obrero. Colección 60 años del Stronismo" (Coronel, 2014a) y "Represión, cooptación y resistencia. El movimiento sindical paraguayo" (González Bozzolasco, 2014) ofrecen una mirada general de la situación de los sindicatos a lo largo del régimen de Stroessner. En tanto que otros, observan periodos más específicos, como los inicios del régimen, analizado en "El movimiento sindical y su resistencia a la consolidación del Régimen Stronista (1955-1959)” (Coronel, 2013), así como su parte final, estudiada en "Sindicalismo y lucha por la democracia (1985-1989)" (González Bozzolasco, 2013d), "El Movimiento Intersindical de Trabajadores del Paraguay: elementos para una primera aproximación histórica” (González Bozzolasco, 2013b) y "El nuevo despertar. Breve historia del Movimiento Intersindical de Trabajadores del Paraguay (1985-1989)" (González Bozzolasco, 2013c). Por su parte, investigaciones como "El último de los tranviarios" (Coronel, 2014b) ofrecen análisis de casos específicos, mientras que trabajos como "Dictadura y Memoria. Vol. 2" (Pérez Cáceres, 2018), presentan testimonios orales de militantes obreros. ${ }^{6}$

\section{LOS ARCHIVOS Y OTROS FONDOS DOCUMENTALES DISPONIBLES}

En lo que refiere a las fuentes documentales y archivos disponibles para el estudio del movimiento obrero paraguayo en general, puede apreciarse que estos resultan extremadamente limitados en comparación con la situación de otros países de la región. En primer lugar, la poca información generada por parte de las instituciones oficiales encargadas de regular las relaciones laborales en el país no se encuentra disponible a investigadores e investigadoras, la documentación producida por estos organismos no fue conservada y, además, no existen archivos pblicos que la colecten y sistematicen. En segundo lugar, las organizaciones sindicales no resguardaron la documentación producida, ya sea por las condiciones adversas que atravesaron durante los años de vigencia del stronismo (en el caso de las organizaciones opositoras al régimen), como por la falta de políticas y estructuras internas de resguardo y/o conservación de toda su producción (en los casos de las organizaciones afines al régimen).

Debido a lo apuntado, los escasos recursos que sí se encuentran disponibles revisten un gran valor para la investigación centrada en la temática obrera en Paraguay. Así, importantes archivos y fondos documentales privados del país han servido como valioso respaldo para investigadores e investigadoras del área. Entre ellos, se destacan el "Archivo Gaona" y la "Biblioteca del Centro de Documentación y Estudios (CDE)".

El "Archivo Gaona”, fue compilado por el dirigente sindical paraguayo Francisco Gaona (1901-1980) y sirvió de base para el desarrollo de su "Historia Social y Gremial del Paraguay" ya mencionada. ${ }^{7}$ Este archivo compila documentación diversa sobre el sindicalismo paraguayo entre los años 1870 y 1979, además de materiales e informaciones acerca del sindicalismo latinoamericano entre los años 1930 y 1950 . El mismo pertenece al Centro de Documentación y Estudios (CDE), organización no gubernamental fundada en 1985, durante los últimos años de gobierno de Alfredo Stroessner. Además, esta organización ofrece en su biblioteca un importante cúmulo de documentación y producción bibliográfica especializada en el movimiento sindical y el conflicto laboral. Fundado por investigadoras e investigadores sociales paraguayos, el CDE tuvo como antecedente inmediato al Banco Paraguayo de Datos (BPD), que funcionó entre los años 1978 y 1983. Tras la represión y arresto de muchos de sus integrantes por parte de las fuerzas de seguridad, el BDP fue clausurado. Sin embargo, el CDE mantiene gran parte de su producción y dio continuidad a los estudios sobre el desarrollo del movimiento obrero y los sindicatos iniciados por el primero. De esta forma, ofrece una producción más o menos sistemática sobre esta temática a lo largo de toda la década de 1980, con análisis específicos del sector, identificación de actores, entrevistas a dirigentes y compilaciones de la prensa escrita.

Aunque no estén particularmente especializados en el movimiento obrero, otros fondos documentales y bibliográficos de carácter privado poseen una importante suma de materiales para su estudio. Se destacan entre ellos la "Biblioteca del Centro Paraguayo de Estudios Sociológicos", la "Fundación Ymaguaré de Imágenes y Libros de Paraguay" y el "Archivo de la Fundación Huellas de la Cultura de Paraguay". Mientras que la primera posee una importante colección de documentos y publicaciones oficiales sobre el mundo 
del trabajo en Paraguay, las dos últimas poseen una diversa compilación de folletos de organizaciones políticas y sociales de los años de gobierno de Stroessner, entre las cuales se encuentra documentación de las organizaciones obreras.

Además de todo lo ya indicado, existen dos fondos documentales importantes que, pese a no estar especializados en la materia, contienen importantes informaciones y documentaciones acerca del movimiento obrero y los sindicatos. Los mismos son: el archivo del "Museo de la Justicia, Centro de Documentación y Archivo para la Defensa de los Derechos Humanos" - Archivos del Terror-y la "Biblioteca Nacional del Paraguay". El primero de ellos depende de la Corte Suprema de Justicia del Paraguay y contiene los archivos de la Policía de la Capital, más específicamente del Departamento de Investigaciones y de la Dirección Nacional de Asuntos Técnicos, desde finales de la década de 1930 hasta inicios de 1990. Los mismos, que son más conocidos como "Los Archivos del Terror", fueron escondidos por las fuerzas policiales tras la caída del gobierno de Stroessner, siendo hallados en 1992 por activistas de derechos humanos. Sus más de 300.000 documentos dan cuenta del funcionamiento de los aparatos de represión policial durante el régimen Stronista. Entre ellos, se encuentra todo el material informativo y documental producido por el Departamento Obrero de la Policía, instancia encargada de controlar a organizaciones, actores y acciones del campo sindical. La segunda institución mencionada, dependiente de la Secretaría Nacional de Cultura, contiene en su hemeroteca un valioso número de publicaciones oficiales, gremiales y de la prensa escrita. Esta colección es, sin dudas, la más completa disponible de forma pública y abierta para la investigación. Al respecto de la temática obrera y sindical se encuentran a disposición gran parte de las publicaciones de prensa editadas bajo el stronismo, muchas de las cuales realizaron sistemáticos seguimientos a las problemáticas gremiales y laborales.

También pueden encontrarse algunos fondos documentales fuera del Paraguay, con archivos especializados y colecciones que contienen información sobre el movimiento obrero paraguayo. Entre ellos, se encuentra el "Archivo Edgard Leuenroth" de la Universidad Estadual de Campinas (Brasil), que guardó en custodia el Archivo Gaona durante los últimos años de vigencia del régimen stronista. Esta situación permitió a los profesionales de esta institución hacer la primera copia microfilmada del mencionado archivo, que en la actualidad se encuentra digitalizado y accesible al público en el portal web de esta institución. Además, este archivo cuenta con la colección de entrevistas de Robert J. Alexander, ${ }^{8}$ que contiene aquellas realizadas en sus visitas a Paraguay, entre las cuales se hallan varias realizadas a militantes, políticos y autoridades públicas vinculadas al mundo del trabajo. Por su parte, la "Biblioteca del Instituto Ibero-Americano" de Berlín (Alemania) posee una significativa colección bibliográfica sobre Paraguay, donde se incluyen varios números de la revista Informaciones del Departamento Nacional del Trabajo (publicación oficial con datos sobre las principales resoluciones y medidas de esta institución). La Universidad de California (Estados Unidos) posee en sus archivos la "Colección Guillermo Arturo Weyer, de la Agencia Noticiosa Paraguaya", con una recopilación de folletos y documentos políticos, que incluye una variedad sustancial de material relacionado con el movimiento sindical.

\section{A MODO DE CONCLUSIÓN: LOS DESAFÍOS PARA UNA NUEVA AGENDA DE INVESTIGACIÓN SOBRE EL MOVIMIENTO SINDICAL PARAGUAYO}

Tal como fue señalado a lo largo de estas líneas, los estudios sobre el sindicalismo y el movimiento obrero forman parte de una ya limitada producción de las ciencias sociales paraguayas. A la escasa existencia de archivos y fuentes disponibles sobre dicha temática, se sumaron las duras condiciones para la producción científica durante los años de vigencia del régimen autoritario, que tornaron dificultoso el desarrollo de este campo de investigación por varias décadas.

Durante los últimos años del stronismo y los primeros de la democracia comenzó a crecer el número de estudios sobre los sindicatos y el movimiento obrero en Paraguay, hasta los inicios de la década del 2000, 
cuando empezaron a mermar. En la década siguiente, en un contexto regional de expansión de los gobiernos progresistas, el actor sindical comenzó a recobrar interés entre las temáticas de investigación en Paraguay. De esta forma, los estudios históricos volvieron a explorar las reducidos, pero aún poco aprovechados archivos $\mathrm{y}$ fondos documentales.

Sin embargo, la producción científica a este respecto se enfrenta aún con varios desafíos a superar. Podrían aquí señalarse al menos dos que, a nuestro criterio, se ubican entre los más importantes. El primero de ellos, consiste en consolidar en Paraguay el campo de los estudios laborales, en general, y de la historia obrera, en particular, con prioridades de investigación bien definidas y extendidas en el tiempo. El segundo desafío es el de impulsar de manera más activa un diálogo con los principales temas estudiados en la región, a partir de una mirada más amplia que piense al Paraguay en un contexto regional (como contrapartida de la permanente mirada particularista, centrada en la búsqueda de la excepcionalidad del "caso paraguayo"). Sin lugar a dudas, la limitada disponibilidad de archivos y fondos documentales sobre la temática obrera es un factor que poco colabora en la superación de los mencionados desafíos. No obstante, dichas condiciones sólo podrán empezar a transformarse, únicamente, a partir de una comunidad científica constituida y con agendas de investigación consolidadas.

\section{RefERENCiAS}

Alba, V. (1964). Historia del movimiento obrero en América Latina. México, D. F.: Libreros Mexicanos Unidos.

Alexander, R. J. (1965). Organized labor in Latin America. New York: The Free Press.

Alexander, R. J., \& Parker, E. M. (2005). A history of organized labor in Uruguay and Paraguay. Westport, Conn: Praeger.

Arditi, B. (1992). Adiós a Stroessner. La reconstrucción de la politica en el Paraguay. Asunción: CDE y RP Ediciones.

Arditi, B., y Rodríguez, J. C. (1987). La Sociedad a pesar del Estado. Movimientos sociales y recuperación democrática en el Paraguay. Asunción: Editorial El Lector.

Barboza, R. (1987). Los sindicatos en el Paraguay. Evolución y estructura actual. Asunción: Editorial El Lector.

Barrett, R. (1911). El dolor paraguayo. Montevideo: Talleres Gráficos El Arte.

Barrett, R. (1926). Lo que son los yerbales paraguayos. Montevideo: Claudio García Editor.

Cardozo, V. (1992). Lucha sindical y transición politica en Paraguay 1990. San José de Costa Rica: EUNA.

Casaccia, G. (1986). Significación de la huelga general de 1958 (Memoria de licenciatura para acceder al título de Licenciada en Sociología). Universidad Católica Nuestra Señora de la Asunción, Asunción.

Casaccia, G. (1991). De la negociación a la ruptura. El significado de la Huelga General de 1958. Asunción: Centro de Documentación y Estudios.

Céspedes, R. (1986). Recesión económica y reconstitución del actor sindical. En D. Rivarola, Los Movimientos Sociales en el Paraguay (pp. 167-208). Asunción: Centro Paraguayo de Estudios Sociológicos.

Céspedes, R. (1989). Las relaciones entre gobierno y sindicalismo en el Paraguay contemporáneo. Estudios Sociológicos, 281-319.

Céspedes, R. (1990). Demanda social y política y autoritarismo en Paraguay (1986-1988). En M. Barrera, Movimientos sociales y politica: El desafio de la democracia en América Latina. Santiago de Chile: CES Ediciones/CLACSO.

Céspedes, R. (1991a). El contrato colectivo en el Paraguay de la transición. Revista Paraguaya de Sociología, 81, 123-149.

Céspedes, R. (1991b). Sindicatos, partidos y transición en Paraguay. En D. Rivarola, M. Cavarozzi y M. A. Garretón, Militares y políticos en una transición atípica (pp. 125-140). Buenos Aires: CLACSO.

Céspedes, R. (1992a). Cambio político y relaciones laborales en el Paraguay. Revista Paraguaya de Sociología, 83. 
Céspedes, R. (1992b). El contrato colectivo en el Paraguay de la transición. En L. Abramo y A. Cuevas, El sindicalismo latinoamericano en los 90: Vol.2. Negociación colectiva y sindicatos (pp. 185-220). Santiago de Chile: Iscos/Clacso/ Cisl.

Céspedes, R. (1993a). Relaciones de trabajo en el Sector Público. Paraguay (1989-1993). Revista Paraguaya de Sociología, 88.

Céspedes, R. (1993b). Sindicalismo y transición. En D. Abente Brun, La transición paraguaya: problemas y perspectivas (pp. 53-68). Caracas: Nueva Sociedad.

Céspedes, R. (2009). Autoritarismo, Sindicalismo y Transición en el Paraguay, 1986-1992. Asunción: Germinal/ Arandura.

Colmán, E. (2002). Nacionalismo e Movimento Operário na origem do Estado Nacional Revolucionário Paraguaio: 1936-1947 (Tesis para obtener el título de Doctor en Historia). Universidade Estadual Paulista, Brasil.

Coronel, J. (2009). Itaipú y la lucha de los trabajadores. Asunción: Germinal/Arandura.

Coronel, J. (2013). El movimiento sindical y su resistencia a la consolidación del Régimen Stronista (1955-1959). Revista Novapolis, 6, 29-48.

Coronel, J. (2014a). El movimiento obrero. Colección 60 años del Stronismo. Asunción: El Lector.

Coronel, J. (2014b). El último de los tranviarios. Asunción: Arandura.

Cristaldo, J. D. (1998). Situación del trabajo en el Paraguay. Actores, problemáticas y desafíos. En Nuevas Relaciones Laborales en el MERCOSUR (pp. 177-248). Buenos Aires: INCASUR.

De la Garza, E. (2016). Los estudios laborales en América Latina antes de la consolidación del neoliberalismo. En E. de la Garza Toledo, Los estudios laborales en América Latina: Orígenes, desarrollo y perspectivas (pp. 19-35). Iztapalapa: Universidad Autónoma Metropolitana - Iztapalapa.

Galeano, L. (2016). Modernización conservadora, tardia y parcial. Historia social escrita durante la dictadura stronista. Asunción: CPES.

Gaona, F. (2007). Introducción a la historia gremial y social del Paraguay (Vol. 1, 2 y 3). Asunción: Germinal/Arandura.

Gómez Romero, C. (2013). El movimiento sindical como actor político de la transición. Revista Novapolis, 6, 73-96.

González Bozzolasco, I. (2013a). Documento de Trabajo No 16: Apuntes teóricos para el estudio de movimiento sindical en la transición democrática paraguaya. Asunción: Centro de Estudios y Educación Popular Germinal.

González Bozzolasco, I. (2013b). El Movimiento Intersindical de Trabajadores del Paraguay: elementos para una primera aproximación histórica. Revista Investigaciones y Estudios de la UNA, 8, 147-169.

González Bozzolasco, I. (2013c). El nuevo despertar. Breve historia del Movimiento Intersindical de Trabajadores del Paraguay (1985-1989). Asunción: Germinal/Arandura.

González Bozzolasco, I. (2013d). Sindicalismo y lucha por la democracia (1985-1989). Revista Novapolis, 6, 49-72.

González Bozzolasco, I. (2014). Represión, cooptación y resistencia. El movimiento sindical paraguayo. En En R. Carbone y L., Soler Stronismo asediado: 2014-1954 (pp. 65-106). Asunción: Germinal/Arandura.

González Bozzolasco, I. (2018). Estado, movimiento obrero y corporativismo en Paraguay. Un análisis del desarrollo institucional y normativo en el periodo 1936-1948. En En L. Ortíz (coord.), Las Ciencias Sociales ante los retos de la Justicia Social. Memorias del I Congreso Paraguayo de Ciencias Sociales (pp. 823-834). Asunción: CLACSO.

González Bozzolasco, I. (2019). Corporativismo y control sindical en Paraguay. Análisis de sus orígenes, actores y marcos institucionales. En L. Aronne de Abreu y M. A. Vannucchi, Corporativismos ibéricos e latino-americanos (pp. 263-284). Porto Alegre: EDIPUCRS.

Lachi, M. (2011).Documento de Trabajo No 9: Diálogo social y tripartismo. Asunción: Centro de Estudios y Educación Popular Germinal.

Lachi, M. (2013). Documento de Trabajo No 17: Las tripartitas del Viceministerio del Trabajo. Un instrumento exitoso del dialogo social (Periodo 2000-2009). Asunción: Centro de Estudios y Educación Popular Germinal. 
Lachi, M. (2014). Documento de Trabajo No 23: La libertad sindical en el Paraguay, según resultados de las denuncias presentadas a los órganos contralores de la OIT (1990-2013). Asunción: Centro de Estudios y Educación Popular Germinal.

Lachi, M. (2016a). Documento de Trabajo No 26: El Dialogo Social en Paraguay. Asunción: Centro de Estudios y Educación Popular Germinal.

Lachi, M. (2016b). Sobre la existencia de la "clase trabajadora" en Paraguay. Un análisis empírico. En L. Ortíz, Desigualdad y clases sociales. Estudios sobre la estructura social paraguaya (pp. 145-166). Asunción: CEADUC/ CLACSO/ICSO.

Lachi, M. y Rojas Scheffer, R. (2016). El diálogo social tripartito en Paraguay, 25 años de intentos y escasos éxitos. Revista Novapolis, 10, 117-140.

Lachi, M. y Rojas Scheffer, R. (2017). Diálogo social, contratación colectiva y tripartismo en Paraguay (1989-2015). Asunción: Germinal/Arandura.

Moran, M. y Villalba, R. (1994). Huelga de 1958 en el relato de sus protagonistas. Asunción: Centro de Documentación y Estudios.

Nickson, A. (1987). Breve historia del Movimiento Obrero paraguayo, 1880-1984. Asunción: Centro de Documentación y Estudios.

Nickson, A. (1989). Paraguay. En J. Carrière, N. Haworth y J. Roddick, The State, Industrial Relations and the Labour Movement in Latin America (pp. 67-98). Londres: The Macmillan Press Ltd.

Nickson, A. (2011). El régimen de Stroessner (1954-1989). En I. Telesca, Historia del Paraguay (pp. 265-294). Asunción: Taurus.

O’Donnell, G., Schmitter, P. C. y Whitehead, L. (1988a). Transiciones desde un Gobierno Autoritario: América Latina. Buenos Aires: Paidós.

O'Donnell, G., Schmitter, P. y Whitehead, L. (1988b). Transiciones desde un Gobierno Autoritario: conclusiones tentativas sobre las democracias inciertas (Vol. 4). Buenos Aires: Paidós.

O'Donnell, G., Schmitter, P. y Whitehead, L. (1988c). Transiciones desde un Gobierno Autoritario: Perspectivas Comparadas. Buenos Aires: Paidós.

O'Donnell, G., Schmitter, P. y Whitehead, L. (1989). Transiciones desde un Gobierno Autoritario: Europa Meridional. Buenos Aires: Paidós.

Pérez Cáceres, C. (2018). Dictadura y Memoria (Vol. 2). Asunción: Ediciones del autor.

Poblete, M., \& Burnett, B. G. (1960). The rise of the Latin American Labor Movement. New York: Bookman Associates.

Rivarola, M. (2010a). Obreros, utopía y revolución. La formación de las clases trabajadoras en el Paraguay liberal 1870/1931. Asunción: Servilibro.

Rivarola, M. (2010b). Vagos, pobres y soldados. La domesticación estatal del trabajo en el Paraguay del siglo XIX. Asunción: Servilibro.

Rodríguez, J. C. (1982). Paraguay. Coyuntura Sindical. Centro de Documentación y Estudios.

Rodríguez, J. C. (1985). L'etat s'empare du mouvement ouvrier (Paraguay 1936-1958) (Memoria de D. E. A.). Ecole des Hautes Etudes en Sciences Sociales, Francia.

Rodríguez, J. C. (1989a). Sindicalismo y transición. Paraguay 1989. Asunción: Centro de Documentación y Estudios.

Rodríguez, J. C. (1989b). Situación actual de la historiografía sobre el movimiento obrero paraguayo. En C. Zubillaga, Trabajadores y sindicatos en América Latina. Reflexiones sobre su historia (p. 200). Montevideo: CLACSO/ CLAEH.

Rodríguez, J. C. (1991a). La formación de una nueva clase obrera. Paraguay 1989-1990. Asunción: Centro de Documentación y Estudios.

Rodríguez, J. C. (1991b). Sindicalismo y transición: Paraguay 1989. En G. Campero y A. Cuevas, El sindicalismo latinoamericano en los noventa: Vol.1. Sindicatos y transición democrática (pp. 195-240). Santiago de Chile: Iscos/ Clacso/Cisl. 
Rodríguez, J. C. (1993). Índice de costo de vida de los obreros y empleados del Gran Asunción. Asunción: Centro de Documentación y Estudios.

Rodríguez,J. C. (2016). Clase obrera en el Paraguay. Herencia y legado post-autoritario. En Desigualdady clases sociales. Estudios sobre la estructura social paraguaya (Luis Ortiz, pp. 121-144). Asunción: CEADUC/CLACSO/ICSO.

Salinas, D. (1984). Movimiento Obrero y Procesos Políticos en Paraguay. En P. González Casanova, Historia del Movimiento Obrero en América Latina [Vol. 3] (pp. 359-421). México, D. F.: Siglo XXI Editores.

Smith, R. E. (1994). Trabajadores y transición paraguaya en perspectiva comparada. Un estudio introductorio. Revista Paraguaya de Sociologia, 90, 131-146.

Soler, L. (2012). Paraguay. La larga invención del golpe. Elstronismo y el orden político paraguayo. Buenos Aires: Imago Mundi.

Soler, L. (2018). Los oficios del sociólogo en Paraguay (1950-1980). Asunción: FLACSO Paraguay-CEPES.

Villalba, R. (1985). Cronología del movimiento obrero paraguayo, 1984. Asunción: Sinatrac/Cepes.

Villalba, R. (1986a). Cronología del movimiento obrero paraguayo, 1985. Asunción: Sinatrac/Cepes.

Villalba, R. (1986b). Relación Estado-Movimiento Obrero. Asunción: Centro de Documentación y Estudios.

Villalba, R. (1987). Cronología del movimiento obrero paraguayo, 1986. Asunción: Centro de Documentación y Estudios.

Villalba, R. (1988). Cronología del movimiento obrero paraguayo, 1987. Asunción: Centro de Documentación y Estudios.

Villalba, R. (1992). Cuadernos de Historia Obrera. 1978 - 1991. Asunción: Centro de Documentación y Estudios.

\section{Notas}

1 Entre los muy escasos trabajos que, aunque de manera muy breve y general, hacen mención del caso paraguayo se ubican los de Moises Poblete y Ben Burnett (1960),Víctor Alba (1964) y Robert J. Alexander (1965).

2 Entre ellos se destacan los trabajos históricos de Milda Rivarola (2010a, 2010b) y José Carlos Rodríguez (1985), producidos como tesis de posgrado, en el marco de estudios realizados a mediados de 1980 durante su exilio.

3 De clara inclinación político-partidaria, Salinas no disimula un análisis de la historia del movimiento obrero que sobresalta el papel del Partido Comunista Paraguayo (PCP), así como su visión de los acontecimientos. A partir de ello, José Carlos Rodríguez (1989b, pp. 100-101) ha llegado a sentenciar que el mismo "[...] es un buen ejemplo de hasta qué punto los prejuicios surgidos de la propia militancia pueden sustituir al estudio de los hechos".

4 Además, Rodríguez coordinó a inicios de la década de 1990 el "Índice de costo de vida de los obreros y empleados del Gran Asunción" (Rodríguez, 1993).

5 También fue producida en 2002 "Nacionalismo e Movimento Operário na origem do Estado Nacional Revolucionário Paraguaio: 1936-1947” (Colmán, 2002), una investigación histórica realizada en base al Archivo Gaona, sin embargo, el corte temporal estudiado no comprende al periodo stronista.

6 Con el mencionado auge de la producción sobre el movimiento obrero y los sindicatos durante los últimos años, nuevos trabajos han abarcado también periodos anteriores al Stronismo (González Bozzolasco, 2018, 2019), como posteriores a este (Gómez Romero, 2013; González Bozzolasco, 2013a; Lachi, 2011, 2013, 2014, 2016a, 2016b; Lachi y Rojas Scheffer, 2016, 2017; Rodríguez, 2016).

7 Francisco Gaona (1901-1980) fue un importante dirigente obrero, con gran protagonismo durante la década del 1930, fundador de la Confederación Nacional de Trabajadores (1936) y primer presidente de esta.

8 Robert J. Alexander (1918-2010), fue un académico e investigador norteamericano, especializado en estudios sobre el movimiento obrero latinoamericano. 